\author{
Military Technical College \\ Kobry El-Kobbah, \\ Cairo, Egypt.
}

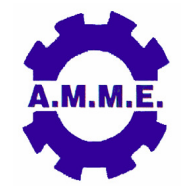

\title{
ASSESSMENT OF DIFFERENT METHODS USED TO ESTIMATE WEIBULL DISTRIBUTION PARAMETERS FOR WIND SPEED IN ZAFARANA WIND FARM, SUEZ GULF, EGYPT
}

\author{
H. Saleh *, A. S. Abou El-Azm** and S. Abdel-Hady **
}

\begin{abstract}
The use of wind as an energy source is becoming popular because of its nonpolluting and renewable features. There is an urgent request to develop site-based estimation on wind engineering, which can be used for optimal design of wind turbines and wind farming. The wind speed for Zafarana Project in Suez Gulf, namely Site-3, based on monthly averaged data for one year as well as every 10 minutes for two days, one day in summer season and one day one winter season have been analyzed to estimate the most appropriate method to find Weibull distribution parameters for this site. The investigated methods are the mean wind speed method, the maximum likelihood method, the modified maximum likelihood method, the graphical method and the power density method. These methods results have been compared with the provided data to find their accuracy based on the root mean square errors. From the obtained results, the mean wind speed and the maximum likelihood method are recommended in estimating the wind speed distribution for the studied site in Zafarana wind farm.
\end{abstract}

\section{KEY WORDS}

Wind speed modelling, Weibull density function, Maximum Likelihood Method, Modified Maximum Likelihood method, Graphical method.

\footnotetext{
* $\quad$ PhD Student, Libyan Armed Forces.

** Egyptian Armed Forces.

*** Professor, South Valley University, Egypt.
} 


\section{NOMENCLATURE}

$\begin{array}{ll}\mathrm{C} & \text { Weibull distribution scale parameter } \\ \mathrm{dv} & \text { Wind speed increment } \\ \mathrm{E}_{\mathrm{f}} & \text { Energy pattern factor } \\ \mathrm{k}_{0} & \text { Shape factor initial value } \\ \mathrm{K} & \text { Dimensionless Weibull distribution shape parameter } \\ \mathrm{n} & \text { Number of wind data points } \\ \mathrm{V}_{\mathrm{ac}} & \text { Actual wind speed data } \\ \mathrm{V}_{\mathrm{M}} & \text { Modelled wind speed using }\end{array}$

\section{Greek}

$\begin{array}{ll}\Gamma() & \text { Gamma function } \\ \sigma & \text { Standard deviation }\end{array}$

\section{Abbreviations}

$\begin{array}{ll}\text { GM } & \text { Graphical method } \\ \text { MMLM } & \text { Modified maximum likelihood method } \\ \text { MLM } & \text { Maximum likelihood method } \\ \text { MWS } & \text { Mean wind speed method } \\ \text { NREA } & \text { New and Renewable Energy Authority } \\ \text { PDM } & \text { Power density method } \\ \text { RMSE } & \text { Root mean square error }\end{array}$

\section{INTRODUCTION}

The energy demand and growing environmental consciousness in the present days apply a need to find energy of clean and renewable resources. In Egypt, the Supreme Council of Energy has approved in 2008 a strategy to diversify the energy resources in the electricity sector and reduces the dependency on fossil fuel by considering a larger contribution from renewable energy resources (NREA 2010). Accordingly, the share of renewable energy in the electricity generation should reach $20 \%$ by the year 2020 and the main part of this renewable energy was assigned to wind energy that should be $12 \%$.

So wind is one of the potential renewable energy resources which can be used in a commercial way. Detailed knowledge of wind characteristics is required for efficient planning and implementation of any wind engineering farm project. These days, there is an urgent need to develop site-based technology on wind engineering, which can be used for optimal design of wind turbines and wind farming. The natural wind, as an energy source, is extremely variable. In order to predict the energy output of a wind energy conversion system (WECS), there has been considerable interest in finding a suitable statistical model of wind speed frequency distribution.

The statistical analysis plays an important role in the wind field for estimating the wind output either the velocity prediction or the power provided. Using the Weibull distribution is a mile stone method through the available statistical methods in 
estimating the wind power. The Weibull distribution is a two-parameter function commonly used to fit a real data collected from a wind farm, it provides a convenient representation of the wind power for estimation and analysis purposes

Many researches have been conducted to estimate the wind velocity distribution using different statistical analysis. Some researches have been highlighted to show the different methodologies used in these statistical analysis.

Dorvlo (2002) investigated the Weibull distribution parameters to model wind speeds at four locations in Oman. The scale and shape parameters were estimated using three methods, the Chi-square method, method of moments and regression method. In the same context, Celik (2003) analyzed the wind energy potential of the region statistically based on one year measured hourly time-series wind speed data.

The probability density distributions are derived from time-series data and distributional parameters are identified. Two probability density functions are fitted to the measured probability distributions on a monthly basis. The wind energy potential of the location is studied based on the Weibull and the Rayleigh models. The Weibull model is better in fitting the measured monthly probability density distributions than the Rayleigh model. This is shown from the monthly correlation coefficient values of the fits. The Weibull model provided better power density estimations in all 12 months than the Rayleigh model.

Also, Chang e al. (2003) reviewed six numerical methods; the moment, empirical, graphical, maximum likelihood, modified maximum likelihood and energy pattern factor method, used for the estimation of the Weibull parameters. A mathematical formulation using a two-parameter Weibull wind speed distribution is established to estimate the wind energy generated by an ideal turbine.

Ettoumi et al. (2003) studied the statistical features of the wind at Oran (Algeria). The data used are the wind speed and wind direction measurements collected every $3 \mathrm{~h}$ at the meteorological station of Es Senia (Oran), during the 1982/92 period. The three-hourly wind data have been modelled by means of Markov chains. The Weibull probability distribution function has been considered and found to fit the monthly frequency distributions of wind speed measurements.

Later, Celik (2004) studied the developments of compressed wind speed data to be used in wind energy and performance calculations of stand alone or hybrid wind energy systems. The data were generated based on the Weibull wind speed distribution model. Two different sets of wind speed data are generated, three and four-day month, each month being represented by 72 and $96 \mathrm{~h}$ of wind speed, respectively. The three and four-day month wind speed data were then used to calculate the monthly energy yields, which, in turn, were compared to those calculated from the measured hourly time series data.

A total of eight years long of measured hourly time series data from five different locations throughout the world were used to validate the method presented. The most important findings are the overall error in the wind energy yield estimation is $3.67 \%$ for the three-day month and $3.21 \%$ for the four-day month and the three- and four-day month compressed wind speed data can be successfully used instead of 
the measured hourly time series data to calculate the wind energy yield over a certain period of time, monthly

Consequently, Perez et al. (2004) analyzed the wind speed evolution and four wind speed intervals for a typical wind turbine were considered. Ten-min averages from sonar placed in an extensive plateau in the North of Spain were considered. Ground influence was present only at lowest levels. As a result, the behaviour of wind speed derived from surface data must be avoided. Although moderate winds were frequent, a persistence analysis revealed the low number of lasting runs.

The wind speed power law was also analyzed and the Weibull parameters were calculated by four methods: linear regression by cumulative frequency, moments, maximum likelihood and quartiles. Finally, height analysis revealed that the shape parameter was around two whereas major differences were reached for the scale factor.

In addition, Vogiatzis et al. (2004) analyzed the data for the years 2000 and 2001 to evaluate the wind potential of the Mikra-Thessaloniki, region in northern Greece. The objective of the analysis was the establishment of the required criteria to the renewable energy sources capable to maintain the operation of a desalination pilot unit. The polar diagrams of the wind (wind speed, frequency, and direction), the mean monthly and annual wind speed profile and the Weibull distributions for the years 2000 and 2001 are presented.

Later, Akpinar and Akpinar (2004) investigated the variations of wind characteristics and wind turbine characteristics in the regions around Elazig, namely Maden, Agin and Keban. Mean wind speed data in measured hourly time series format is statistically analyzed for the six year period 1998-2003. The probability density distributions are derived from the time series data and their distributional parameters are identified. Two probability density functions are fitted to the measured probability distributions on a seasonal basis. The wind energy characteristics of all the regions is studied based on the Weibull and Rayleigh distributions. It was found that Maden is the best region, among the regions analyzed, for wind characteristics and wind turbine characteristics.

While Toure (2005) applied a new method to identify the 2-parameter Weibull distribution. The differential equation was identified. Then the study disclosed a linear relationship with two Eigen-coordinates. The results showed a better reliability. The Eigen-coordinates method is applied to the 2-parameter Weibull distribution. The results were compared with those found by the regression method. The study disclosed a better reliability of the fitting by the Eigen-coordinates method.

After that, Xiao et al. (2006) investigated the probability distributions of extreme wind speed and its occurrence interval based on extreme wind speed data recorded in Hong Kong. The three-parameter Weibull distribution and two-parameter Weibull distribution are adopted in this study to fit the wind speed data. It is found that the three-parameter Weibull distributions are more appropriate than the two-parameter Weibull distribution. It is also observed that the occurrence interval of a specified extreme wind speed is a random variable which follows the three-parameter or the 
two-parameter Weibull distribution, while the two-parameter Weibull model is a better choice.

Also, Kiss and Jánosi (2008) evaluated surface wind velocity records of the ERA-40 data base covering 44 years with a temporal resolution of 6 hours. They tested the well known distribution functions; Rayleigh, binormal, Weibull and lognormal, and observed that the popular Weibull function performs supremely. They found that the generalized gamma distribution, which has independent shape parameters for both tails, provides an adequate and unified description almost everywhere.

The geographical distribution of the fitted parameters reveals the possible climatological origin of different wind speed distributions. They also found that the Weibull model can indeed adequately characterize wind histograms over the seas and over some parts of land areas as well.

Akdag and Dinler (2009) developed a new method to estimate Weibull distribution parameters for wind energy applications, named power density (PD) method. In this study, the graphic, maximum likelihood and moment methods, are revisited and a comparison between these methods and PD method is carried out. Suitability of these methods is judged based on different goodness of fit tests for different geographical locations.

Also, Jowder (2009) statically analyzed the hourly measured wind speed data for years 2003-2005 at $10 \mathrm{~m}, 30 \mathrm{~m}$ and $60 \mathrm{~m}$ height for Kingdom of Bahrain to determine the potential of wind power generation using Weibull distribution; the graphical method and the another method.

Later, Islam et al. (2011) estimated the performance of a wind in a planning wind energy project. In their study, with the help of 2-parameter Weibull distribution, the assessment of wind energy potentiality at Kudat and Labuan in 2006-2008 was carried out. The monthly and yearly highest mean wind speeds were $4.76 \mathrm{~m} / \mathrm{s}$ at Kudat and $3.39 \mathrm{~m} / \mathrm{s}$ at Labuan respectively. The annual highest values of the Weibull shape parameter and scale parameter were 1.86 and $3.81 \mathrm{~m} / \mathrm{s}$ respectively. The maximum deviation, at wind speed more than $2 \mathrm{~m} / \mathrm{s}$, between observed and Weibull frequency distribution was about $5 \%$. They concluded that these sites are unsuitable for the large-scale wind energy generation.

Chang (2011) studied six kinds of numerical methods commonly used for estimating Weibull parameters are reviewed; the moment, empirical, graphical, maximum likelihood, modified maximum likelihood and energy pattern factor method. Their performance is compared through Monte Carlo simulation and analysis of actual wind speed according to the criterions such as Kolmogorov-Smirnov test, parameter error, root mean square error, and wind energy error. The results shown the graphical method's performance in estimating Weibull parameters is the worst one, followed by the empirical and energy pattern factor methods, if data number is smaller. The performance for all the six methods is improved while data number becomes larger; the graphical method is even better than the empirical and energy pattern factor methods. Also in the analyses of actual wind data obtained from different climatic situations, it is found that the six methods are applicable if wind speed fits well with theoretical Weibull function. 
Mirhosseini et al. (2011) studied the 3-h period measured wind speed data for years 2003-2007 at $10 \mathrm{~m}, 30 \mathrm{~m}$ and $40 \mathrm{~m}$ heights for one of the provinces of Iran. Semnan have been statistically analyzed to determine the potential of wind power generation. They presented the wind energy potential at five towns in the province - Biarjmand, Damghan, Garmsar, Semnan, and Shahrood.

Extrapolation of the $10 \mathrm{~m}$ data, using the Power Law, has been used to determine the wind data at heights of $30 \mathrm{~m}$ and $40 \mathrm{~m}$. From the primary evaluation and determining mean wind speed and also Weibull distribution, it is found that Damghan has better potential for using wind energy in the province.

In the present study, the measured wind speed every month for one year as well as every 10 minutes for two days, one day in summer season and one day in winter season, in Site-3 of Zafarana wind farm at Suez Gulf have been analyzed statistically. This analysis has been performed to find the most suitable method to estimate the Weibull distribution parameters based on root mean square error for the wind speed analysis purposes.

Zafarana wind farm, located in Suez Gulf, is approximately $200 \mathrm{~km}$ south east Cairo at the southern border of $\mathrm{N} 27^{\circ} 40^{\prime} 5^{\circ}$ and northern point of E $33^{\circ} 11^{\prime} 31.4^{\prime \prime} / \mathrm{N} 28^{\circ}$ $12^{\prime} 1.5^{\prime \prime}$ as shown in Fig. 1. The site consists of 8 wind farms of different power outputs of total $545 \mathrm{MW}$ and with averaged wind speed of $9 \mathrm{~m} / \mathrm{s}$.

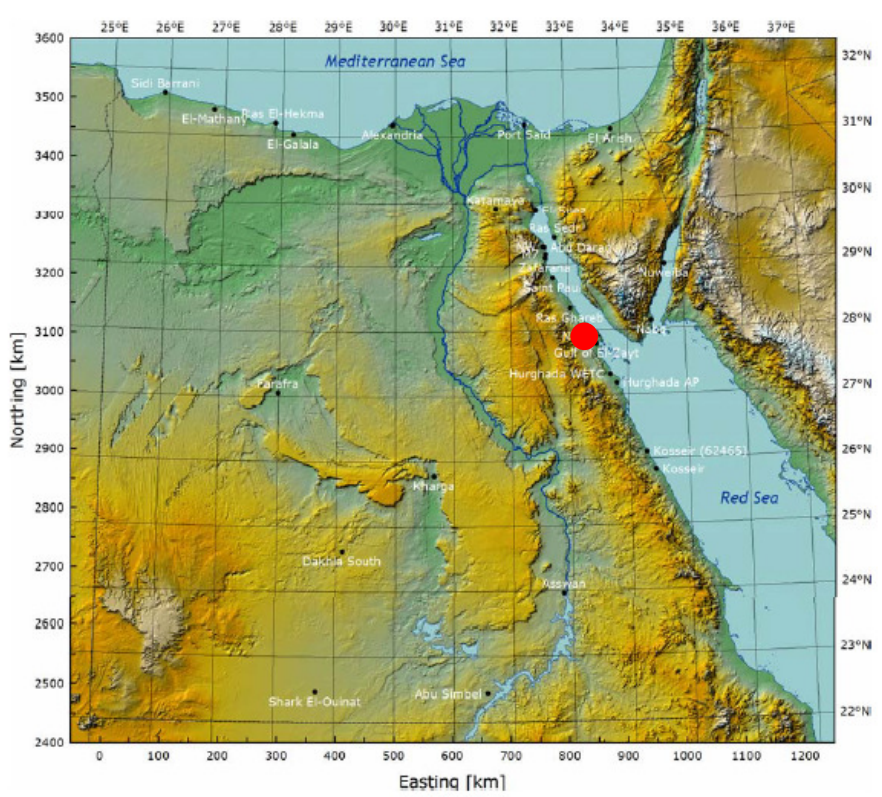

Fig. 1. Map of Egypt and location of Zafarana wind farm in Suez Gulf.

The studied wind farm in Zafarana, namely Site-3, consists of 46 wind turbines (three-blade upwind machine with active yaw) of $660 \mathrm{KW}$ with a total site power output of $30 \mathrm{MW}$. The wind turbines are of Vestas type, V47-660/200kW, of pitch control and the studied Site-3 has been commissioned with cooperation with DANIDA on November 2003. 
The field measured data were collected for averaged monthly wind speed for one year from July 2010 to June 2011 and every 10 minutes wind speed for two days, one day in summer $10^{\text {th }}$ of July 2010 and one day in winter $10^{\text {th }}$ of March 2011.

The Weibull parameters have been estimated using six methods; mean wind speed method, the maximum likelihood method, the modified maximum likelihood method, the graphical method and the power density. The root mean square errors (RMSE) for the fitted Weibull distribution and the actual frequency distribution have been used to determine the best wind speed modelled methods for wind speed analysis purposes.

This paper is organized as follows; the wind data will be introduced in section two, then the theoretical framework of the wind speed estimation using different methods will be illustrated in section three. The results will be presented in section four and then the conclusions will be addressed in section five.

\section{WIND DATA}

The collected wind speed for averaged are presented in time series format, in which each data represents an instantaneous sample averaged of wind speed over the time mentioned intervals, shown in Figs. 2 to 6 .

Based on these plots, the maximum wind speed is located in summer season; in June, July, August and September, of values 9, 9.6, 9.2 and 9.2 respectively. While the minimum wind speed is located in winter season; in January, February and April, of values $5.2,5.5$ and 5.7 , respectively.

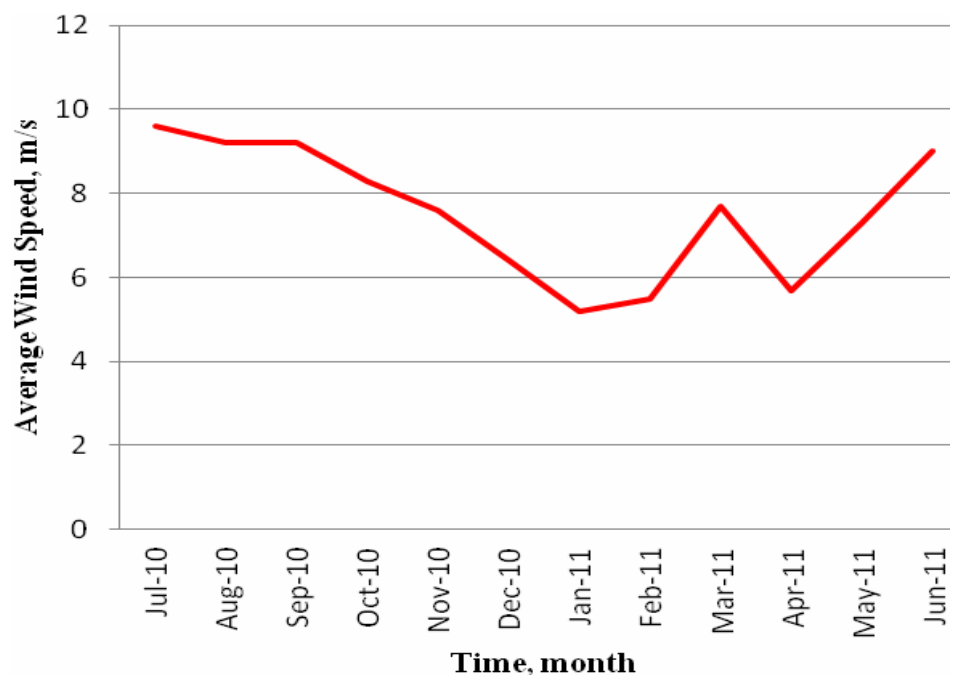

Fig. 2. Field monthly averaged wind speed in Site-3 for a year, Zafarana wind farm.

The averaged wind speed over one year of value 7.6 is not equal to the designed averaged wind speed of $9 \mathrm{~m} / \mathrm{s}$, this may be reasoned by the change of the landscape building which may affect the wind speed in the wind farm. In addition, the 


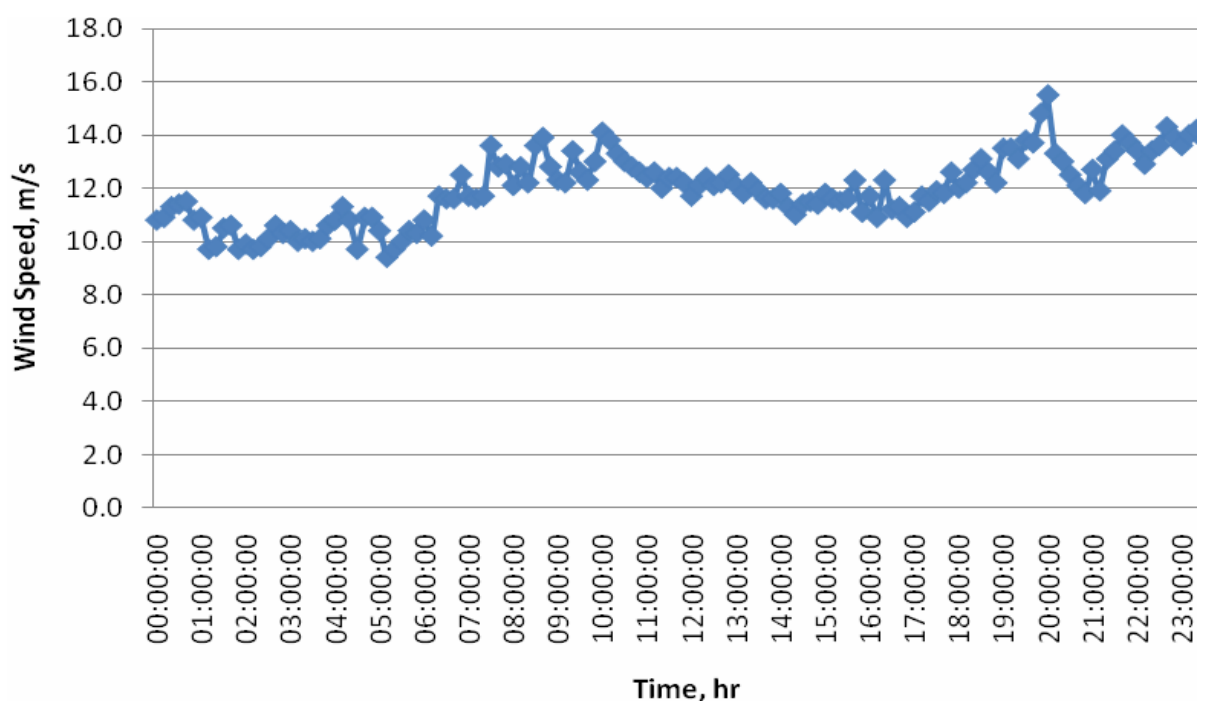

Fig. 3. Measured wind speed every 10 minutes in $10^{\text {th }}$ of July 2010 , Zafarana wind farm.

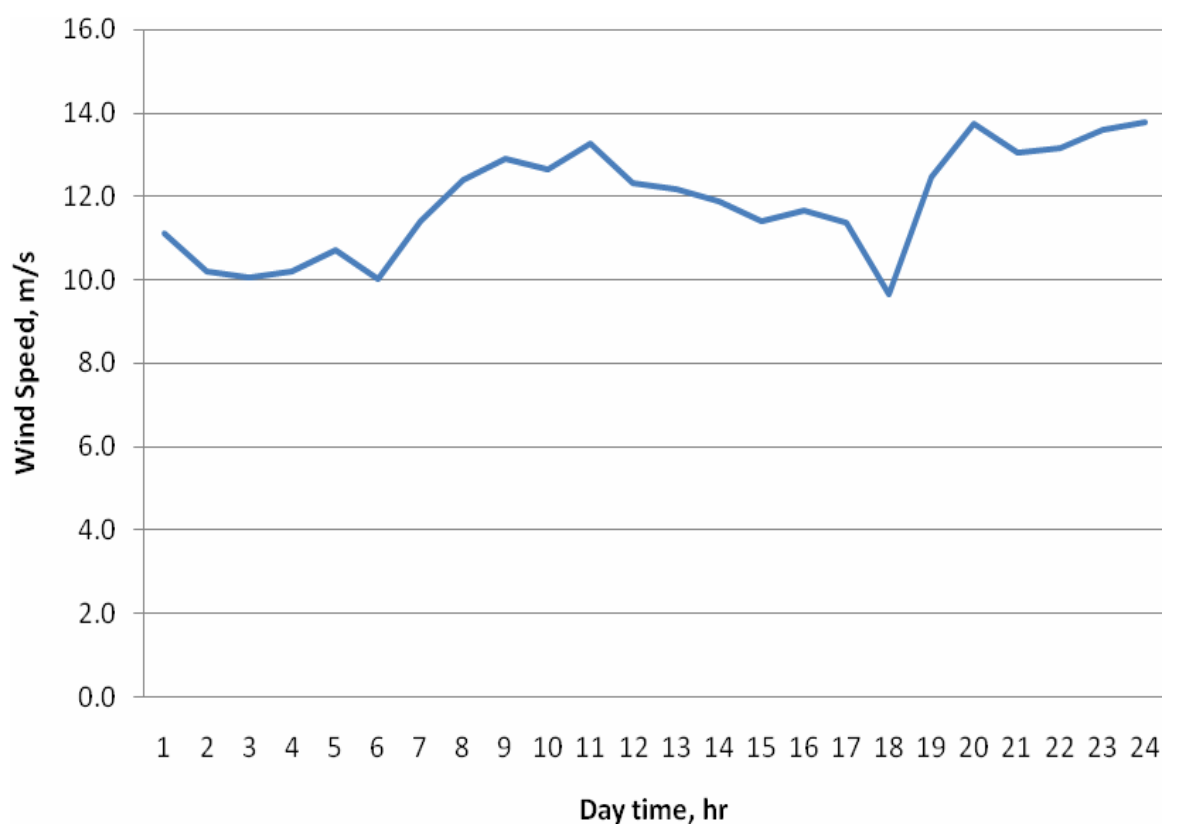

Fig. 4. Hourly averaged wind speed in $10^{\text {th }}$ of July 2010 , Zafarana wind farm.

maximum wind speed in a selected summer day, $10^{\text {th }}$ of July 2010 , is $12 \mathrm{~m} / \mathrm{s}$ while in a selected winter day, $10^{\text {th }}$ of March 2011 , is $3.8 \mathrm{~m} / \mathrm{s}$.

The filed data used in this study could be converted to the frequency distribution format whereby the frequency with which the wind speed falls within various ranges as shown in Figs. 7 to 10, in these figures the frequency of the data could be noticed. For the summer season the peak of the wind speed of $12 \mathrm{~m} / \mathrm{s}$ has a frequency of 27 $\%$ while in the winter season the wind speed of $4 \mathrm{~m} / \mathrm{s}$ has a frequency of $34 \%$. 


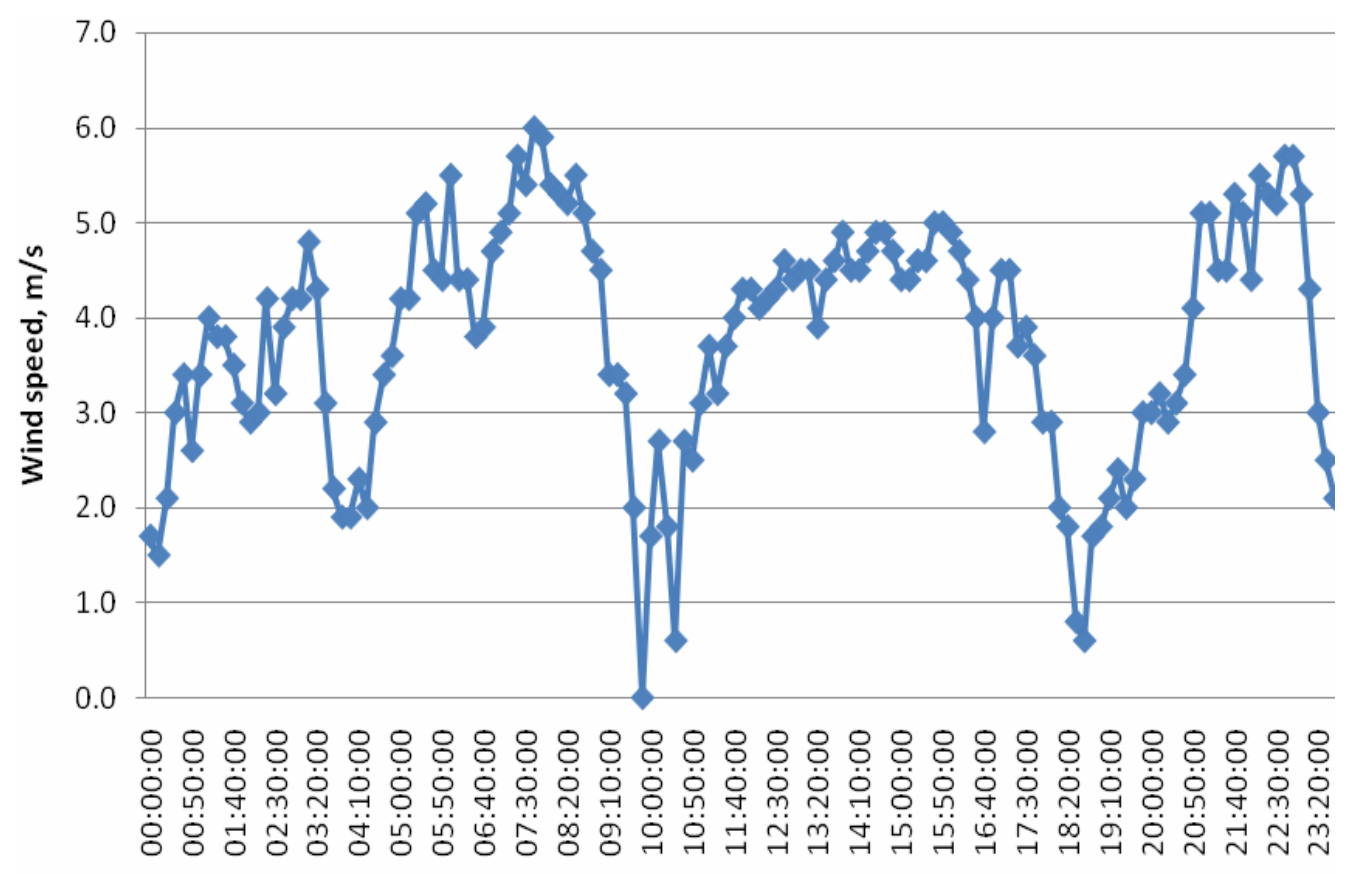

Time, hr

Fig. 5. Measured wind speed every 10 minutes in $10^{\text {th }}$ of March 2011, Zafarana wind farm.

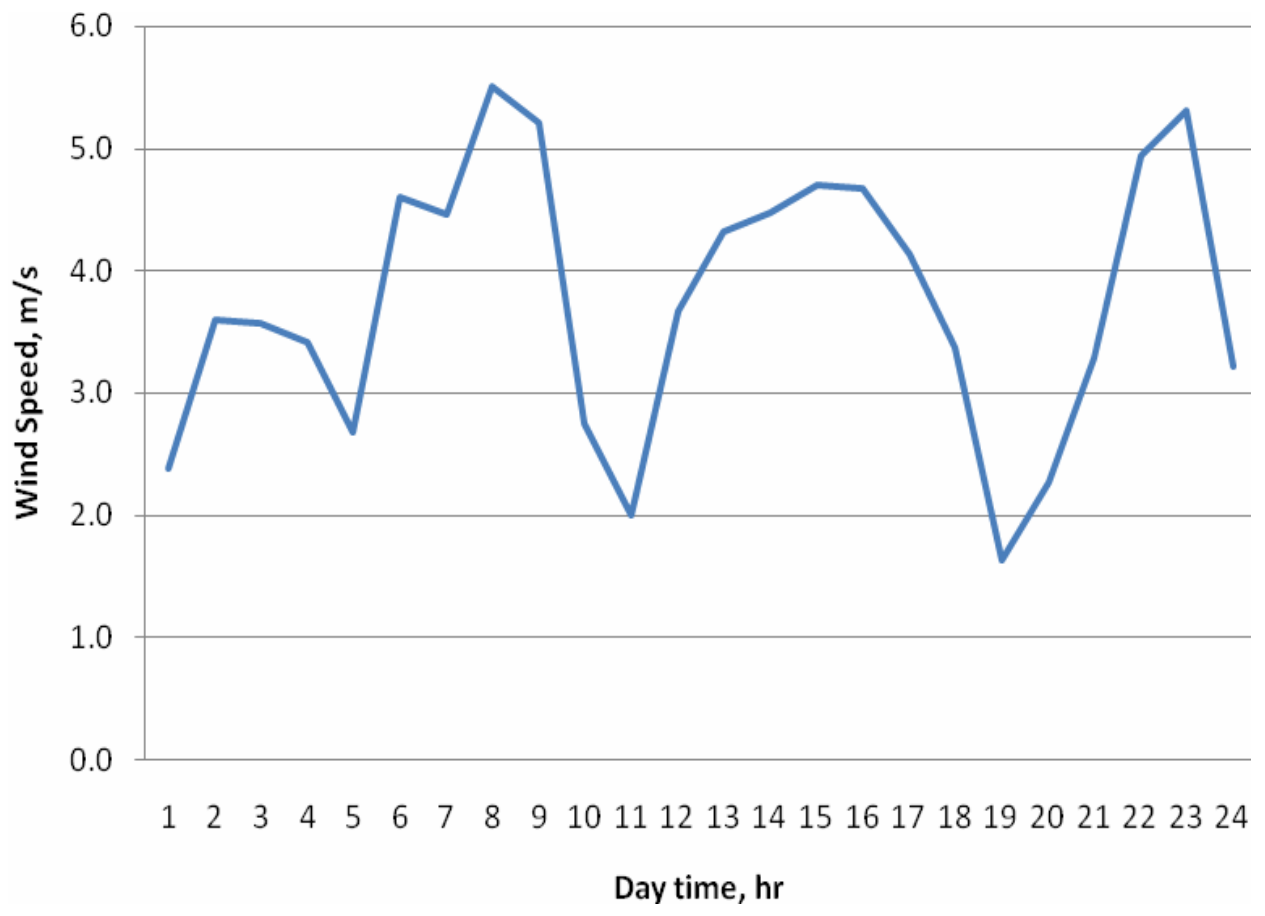

Fig. 6. Hourly averaged wind speed in $10^{\text {th }}$ of March 2011 , Zafarana wind farm. 


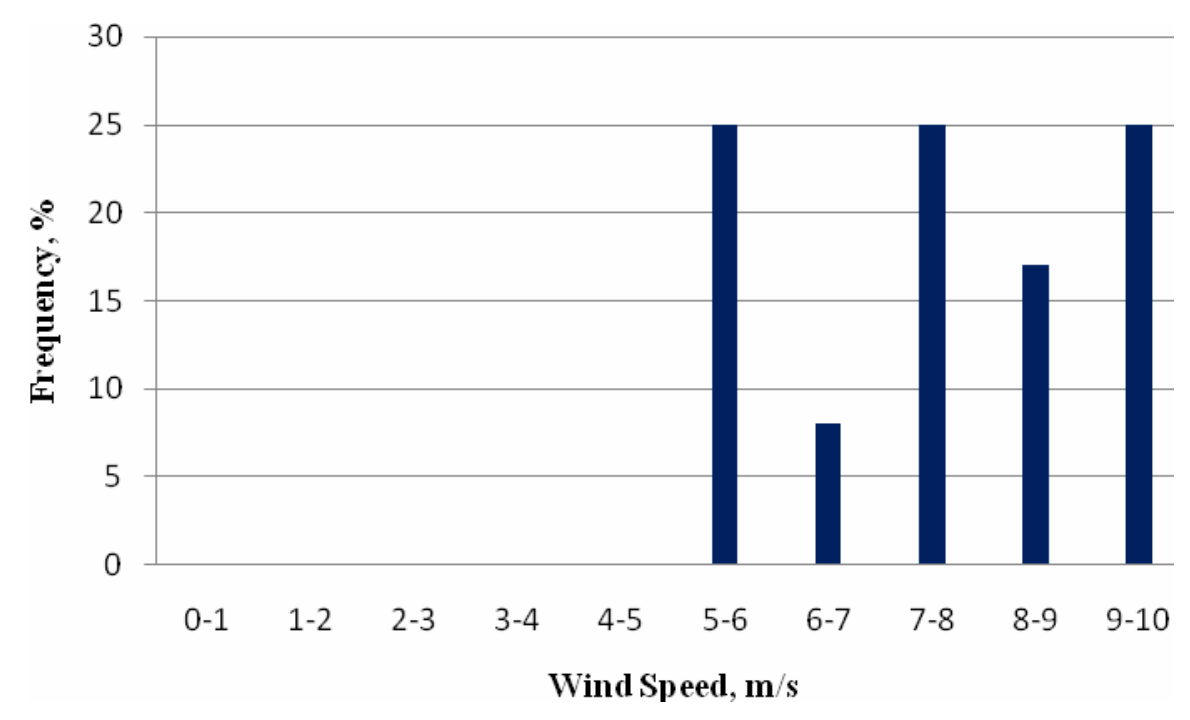

Fig. 7. Field monthly averaged wind speed frequency, \%.

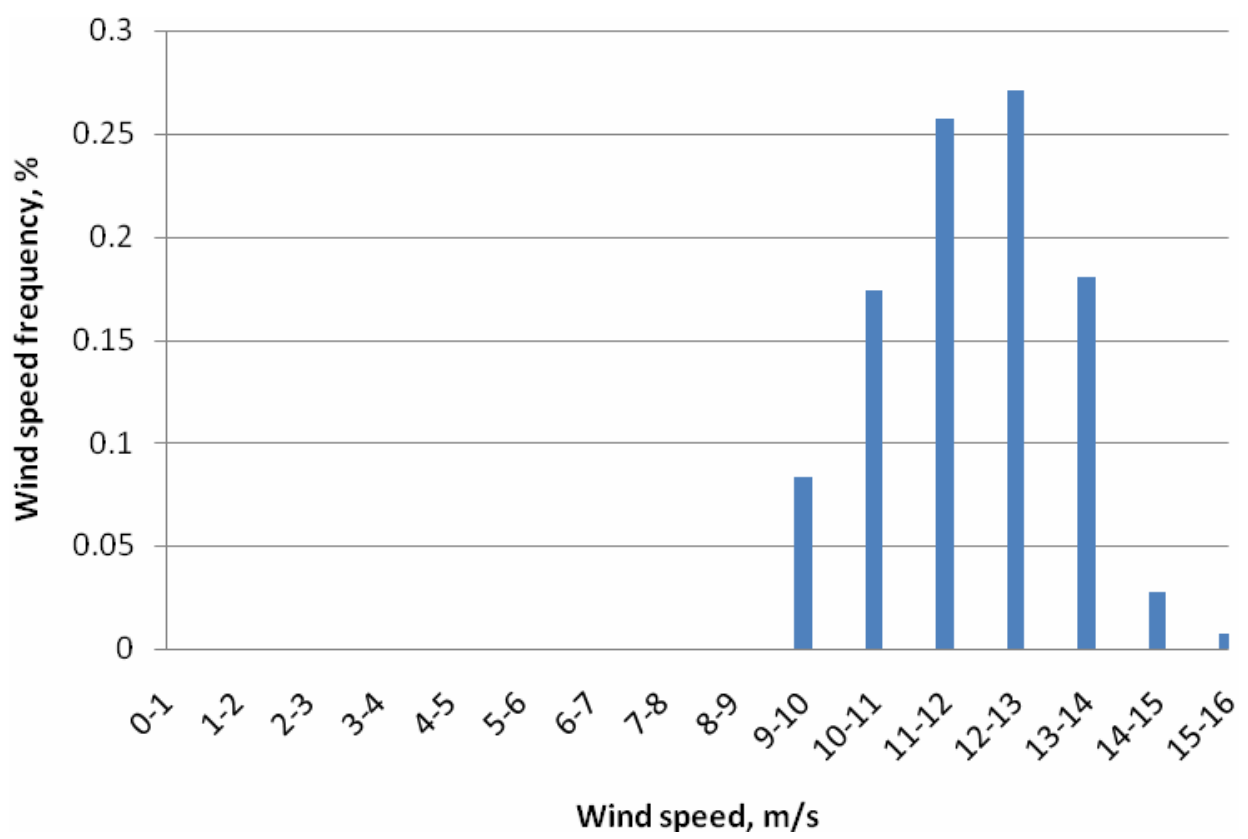

Fig. 8. Measured wind speed every 10 minutes frequency in summer season, data for 10th of July 2010. 


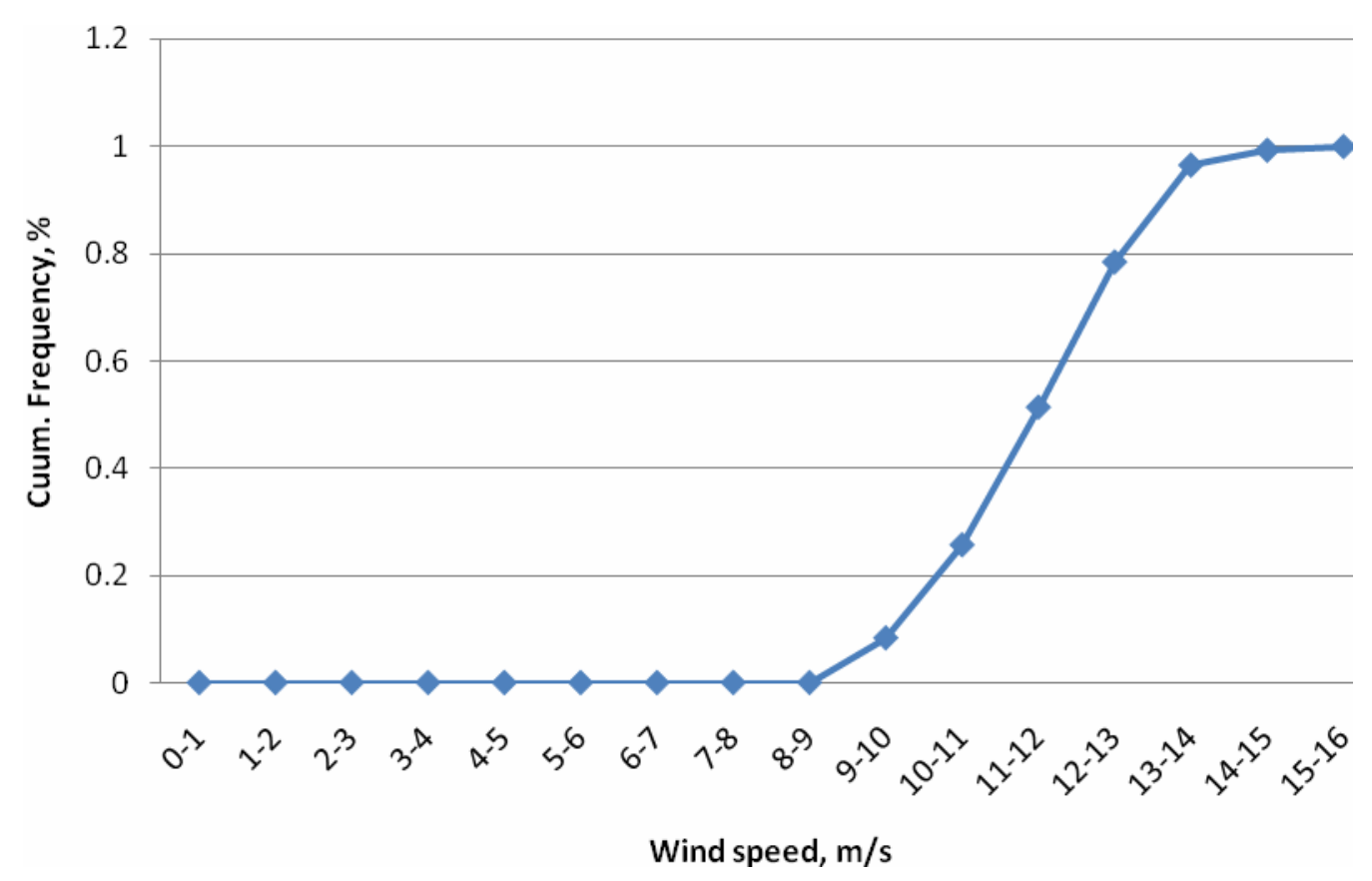

Fig. 9. Measured wind speed every 10 minutes cumulative frequency in summer season, data for 10th of July 2010.

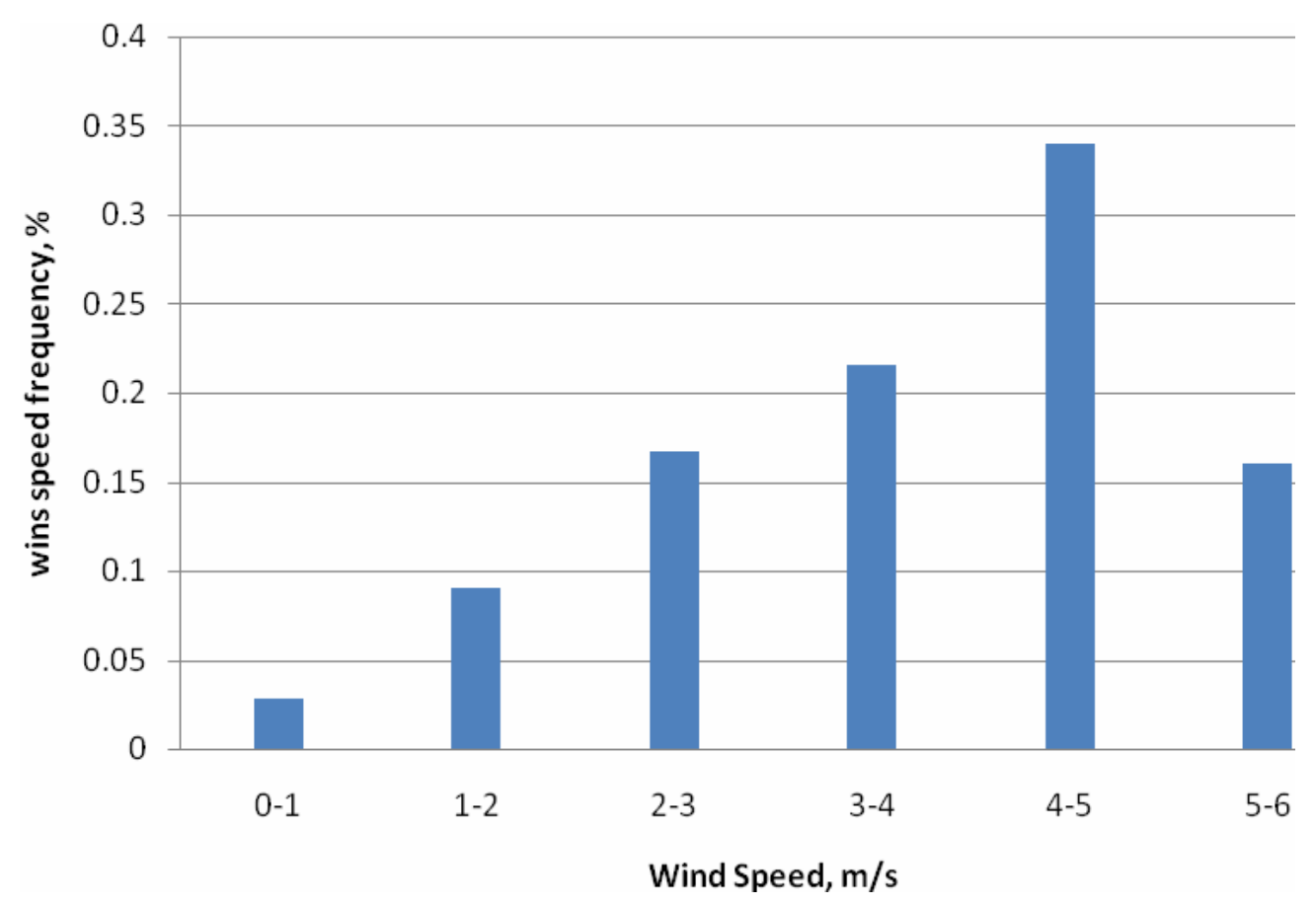

Fig. 10. Measured wind speed every 10 minutes frequency in winter season, data for 10th of March 2011. 
The statistical information for this analysis has been tabulated in Tables 1:

Table.1. Statistical parameters of measured monthly and every 10 minutes wind speed data in Zafarana, Site-3.

\begin{tabular}{|c|c|c|c|}
\hline \multirow{3}{*}{ Parameter } & \multicolumn{3}{|c|}{ Data for Zafarana wind farm, Site-3 } \\
\hline & \multicolumn{2}{|c|}{ Daily wind speed (m/s) } & \multirow{2}{*}{$\begin{array}{c}\text { Monthly } \\
\text { Wind Speed } \\
(\mathrm{m} / \mathrm{s})\end{array}$} \\
\hline & $10^{\text {th }}$ July 2010 & $10^{\text {th }}$ March 2011 & \\
\hline Mean & 12 & 3.8 & 7.55 \\
\hline Variance & 1.6 & 1.53 & 2.38 \\
\hline Standard Deviation & 1.26 & 1.23 & 1.49 \\
\hline Minimum & 9.4 & 0 & 5.2 \\
\hline Maximum & 15.5 & 6 & 9.6 \\
\hline Sample size & 144 & 144 & 12 \\
\hline
\end{tabular}

The published data in Moussa (2000) for Zafarana wind farm has been highlighted in Table 2 for the main parameters for the Weibull distribution parameters.

Table.2. Overall summary 1991-1995 of wind observations at the Zafarana stations, on monthly base, (Moussa, 2000).

\begin{tabular}{|l|c|}
\hline \multicolumn{1}{|c|}{ Station } & Zafarana \\
\hline \hline Data Recovery rate, $\mathrm{R},(\%)$ & 77 \\
\hline Weibull Shape factor, $\mathrm{k}$ & 3.42 \\
\hline Weibull Scale factor, $\mathrm{c}, \mathrm{m} / \mathrm{s}$ & 10.4 \\
\hline Mean wind velocity, $\mathrm{U}, \mathrm{m} / \mathrm{s}$ & 9.1 \\
\hline Mean energy density, $\mathrm{E}, \mathrm{W} / \mathrm{m}^{2}$ & 652 \\
\hline Direction, , DU, Deg. & 001 \\
\hline
\end{tabular}

\section{THE WEIBULL DISTRIBUTION}

The analysis of wind energy regime before developing any wind energy project is a fundamental step as the cost of generating energy is heavily dependent on the wind resources at this site. The wind resources in any site are critically influenced by the wind speed which relate in a cubic relation to the wind generated power. Accordingly, the averaged wind speed is important information in assessing the site wind energy potential.

In literature, there are several density functions which can be used to describe the wind speed distribution. The most two common distributions are the Weibull and the Rayleigh functions in which the Rayleigh distribution is a subset of the Weibull distribution. The reason for that because their easy estimation of their parameters. The Weibull is a two parameter distribution while the Rayleigh has only one parameter. 
This makes the Weibull somewhat more versatile and the Rayleigh somewhat simpler to use. In recent studies (Tar, 2008), other two distributions, the gamma and the square-root normal distributions were compared to the Weibull distribution. It is found that all three models give a good agreement to the observed values of wind speed but the Weibull distribution was recommended for its simplicity.

The Weibull Cumulative distribution function for the wind speed is given by:

$F(v)=1-\exp \left[-\left(\frac{v}{c}\right)^{k}\right]$

and the Weibull probability distribution function is given by:

$f(\mathrm{v})=\frac{d F(v)}{d v}=\left(\frac{k}{c}\right)\left(\frac{v}{e}\right)^{k-1} \exp \left[-\left(\frac{v}{c}\right)^{k}\right]$

The averaged wind speed is given by:

$\overline{\mathrm{v}}=\int_{0}^{\infty} v f(v) d v=\int_{0}^{\infty} v\left(\frac{k}{c}\right)\left(\frac{v}{c}\right)^{k-1} \exp \left[-\left(\frac{v}{c}\right)^{k}\right] d v$

which can be simplified to:

$\overline{\mathbf{v}}=\boldsymbol{c} \int_{0}^{\infty}(x)^{k-1} \exp \left[-(x)^{k}\right] d x$

$\mathrm{x}=\left(\frac{v}{c}\right)^{k-1}$

By using the Gamma function, the averaged speed could be introduced as follows:

$\overline{\mathbf{v}}=c \Gamma\left(1+\frac{1}{k}\right)$

Then

$c=\frac{\bar{v}}{\Gamma(1+1 / k)}$

where $\mathrm{c}$ is the Weibull scale parameter, with units equal to the wind speed units, $\mathrm{k}$ is dimensionless Weibull shape parameter, $v$ is wind speed, $d v$ is the wind speed increment, $\bar{v}$ is the average wind speed and $\Gamma()$ is the Gamma function. The higher value of Weibull distribution scale parameter, $\mathrm{c}$, indicates that the wind speed is higher, while the values of Weibull distribution shape parameter, $k$, indicated the wind stability. If the shape parameter is exactly 2 , then the distribution is called the cumulative Rayleigh distribution. Manufacturers of wind turbines generally give the standard performance of their machines using the Rayleigh distribution.

There are several methods for calculating the parameters, $\mathrm{k}$ and $\mathrm{c}$, of the Weibull distribution for wind speed analysis such as:

- Mean wind speed and standard deviation, MWS.

- The maximum likelihood method, MLM.

- The modified maximum likelihood method, MMLM.

- The commonly used graphical method, GM.

- The Power density method, PDM. 


\section{Mean Wind Speed and Standard Deviation}

By knowing the wind speed variations, the averaged wind speed could be calculated and a preliminary estimation for the Weibull distribution parameters could be found.

$c=\frac{\bar{v}}{\Gamma(1+1 / k)}$

The value of $k$ could be estimated as follows, (Ramirez and Carta, 2005):

$\mathbf{k}=(\boldsymbol{\sigma} / \overline{\mathbf{v}})^{-1.086}$

$(1 \leq k \leq 10)$

where $\bar{v}$ is the averaged wind speed and $\sigma$ is the standard deviation of the wind speed series.

\section{The Maximum Likelihood Method}

The Weibull distribution can be fitted to time-series speed data using the maximum likelihood method (MLM). Then from the MLM, the parameters of the Weibull distribution function, the shape factor, $\mathrm{k}$, and the scale factor, $\mathrm{c}$, could be found.

Assume $\left(v_{1}, v_{2}, v_{3}, \ldots, v_{n}\right)$ is a random sample with a probability density function of the Weibull distribution of the form in Equation 2. The likelihood function of this random sample is $L\left(k, c, v_{1}, v_{2}, v_{3}, \ldots, v_{n}\right)$ is the joint density of the variables involved as follows:

$\mathbf{L}\left(\mathbf{k}, \mathbf{c}_{n} \mathbf{v}_{1,} \mathbf{v}_{2}, \mathbf{v}_{3}, \ldots, \mathbf{v}_{\mathbf{n}}\right)=\prod_{i=1}^{\mathrm{n}} \mathbf{f}\left(\mathbf{k}, \mathbf{c}_{n}, \mathbf{v}_{\mathrm{i}}\right)$

then:

$\ln L=\sum_{i=1}^{n} \ln \left[f\left(v_{i}\right)\right]$

$\ln L=\mathbf{n}[\ln k-k \ln c]+(k-1) \sum_{i=1}^{n} \ln \left(v_{i}\right)-c^{-k} \sum_{i=1}^{n}\left(v_{i}\right)^{k}$

For $\mathrm{n}$ independent samples, the maximum of the Likelihood function is denoted by solving the system of equation:

$\left\{\begin{array}{l}\frac{\partial \ln L}{\partial k}=0 \\ \frac{\partial \ln L}{\partial c}=0\end{array}\right.$

The solution of this system of equation should satisfy the following system of equation:

$\left\{\begin{array}{c}\hat{c}=\left(\frac{1}{n} \sum_{i=1}^{n} v_{i}\right)^{\frac{1}{\hat{k}}} \\ \frac{n}{\hat{k}}-n \ln (\hat{c})+\sum_{i=1}^{n} \ln \left(v_{i}\right)-\sum_{i=1}^{n}\left(\frac{v_{i}}{\xi}\right)^{\hat{k}} \ln \left(\frac{v_{1}}{\hat{c}}\right)=0\end{array}\right.$ 
By eliminating the $\mathrm{c}$ variable from the above system of equation, the following equations could be obtained:

$$
\begin{aligned}
& \hat{\mathbf{k}}=\left(\frac{\sum_{1=1}^{\mathrm{n}} \mathrm{vi}^{\mathrm{k}} \ln (\mathrm{vi})}{\sum_{i=1}^{\mathrm{n}} \mathrm{vi}^{\mathrm{k}}}-\frac{\sum_{1=1}^{\mathrm{n}} \ln (\mathrm{wi})}{\mathrm{n}}\right)^{-1} \\
& \mathbf{c}=\left(\frac{1}{\mathrm{n}} \sum_{\mathrm{i}=1}^{\mathrm{n}} \mathbf{v}_{\mathrm{i}}^{\mathrm{k}}\right)^{1 / \mathrm{k}}
\end{aligned}
$$

where $v_{i}$ is the speed in time step $i$ and $n$ is the number of nonzero wind speed data points, Equation (15) must be solved using an iterative procedure. A Matlab program has been assigned to find shape factor, $k$, by the iteration starting from an initial value of $k_{0}$ and finally reaching the convergence value of $k$, and then the value of scale factor, c, could be found.

\section{The Modified Maximum Likelihood Method}

When wind speed data are available in frequency distribution format, a variation of the maximum likelihood method can be applied. The Weibull parameters are estimated using the following two equations:

$$
\begin{aligned}
& \mathbf{k}=\left(\frac{\sum_{i=1}^{\mathrm{n}} \mathrm{vi}^{\mathrm{k}} \ln (\mathrm{wi}) \mathrm{P}(\mathrm{pi})}{\sum_{i=1}^{\mathrm{n}} \mathrm{vi}^{\mathrm{k}} \mathrm{P}(\mathrm{vi})}-\frac{\sum_{i=1}^{\mathrm{n}} \ln (\mathrm{vi}) \mathrm{P}(\mathrm{vi})}{\mathrm{P}(\mathrm{v} \geq 0)}\right)^{-1} \\
& \boldsymbol{c}=\left(\frac{1}{\mathrm{P}(\mathrm{v} \geq 0)} \sum_{\mathrm{i}=1}^{\mathrm{n}} \mathbf{v}_{\mathrm{i}}^{\mathrm{k}} \mathbf{P}\left(\mathbf{v}_{\mathrm{i}}\right)\right)^{1 / k}
\end{aligned}
$$

where $v_{i}$ is the wind speed at time interval $i, n$ is the number of points, $\mathrm{P}\left(v_{i}\right)$ is the frequency with which the wind speed falls within point $i, P(v \geq 0)$ is the probability that the wind speed equals or exceeds zero. Equation (17) must be solved iteratively. A Matlab program has been designed to solve this equation with an initial value of $k$ equal 2.

\section{The graphical method}

From Equation (1), the cumulative distribution function could be changed to a linear function as following relation:

$$
\begin{aligned}
& 1-F(v)=\exp \left[-\left(\frac{v}{c}\right)^{k}\right] \\
& \frac{1}{1-F(v)}=\exp \left[-\left(\frac{v}{c}\right)^{k}\right] \\
& \ln \{-\ln [1-F(v)]\}=k \ln v-k \ln c
\end{aligned}
$$

The plot of $\operatorname{In}\{-\ln [1-F(v)]\}$ against In $v$ demonstrates a straight line with a slope of $k$ and an intersection with the $x$-axis of $(-k \ln c)$. This logarithmic transformation is the basis of the graphical method. 


\section{Power Density Method}

This is a new method that to be used estimating scale and shape parameters and it has a simpler formulation, easier implementation and also requires less computation. Energy pattern factor, $\mathbb{E}_{\mathrm{pf}}$, is the ratio of mean wind speed $\overline{\mathrm{V}}^{3} /(\overline{\mathrm{V}})^{3}$

$$
\frac{\bar{v}^{3}}{(\bar{v})^{3}}=\frac{\Gamma(1+3 / h)}{\Gamma(1+1 / k)^{3}}
$$

Weibull parameters can be estimated with solving energy pattern factor numerically or approximately by Power Density method, PD, using this simple formula:

$\mathbf{k}=\mathbf{1}+\frac{3.69}{\left(\mathrm{E}_{\mathrm{pf}}\right)^{2}}$

Also scale parameter is estimated by:

$c=\frac{\overline{\mathrm{v}}}{\Gamma(1+1 / \mathrm{k})}$

Superiority of the Power Density method are that; it has a simple formulation, it does not require binning and solving linear least square problem or iterative procedure and finally If power density and mean wind speed are available it is very simple to estimate Weibull parameters.

\section{RESULTS}

\section{Statistical Modelling of Wind Speed Based on Averaged Monthly Data}

The wind speed is modelled using statistical method of Weibull distribution. The Weibull distribution parameters were estimated using different methods. These methods were evaluated to have the suitable method to be applied to estimate the Weibull distribution for Zafarana wind farm. The data collection from Zafarana Wind Farm, Site-3 project, for averaged monthly basis is analyzed using above method then comparison between these different methods have been made, Fig. 11 to 14 . In Fig. 11, the shape factor value with iterations has been plotted using the MLM method; a convergence of the iterations could be achieved. While in Fig. 12 to 14, a comparison between the actual wind speed distribution and the wind speed distribution based on Weibull distribution have been plotted using MLM and MMLM methods.

In Fig. 15 a comparison has been made for the collected data for the wind speed and that modeled using Weibull distribution introducing different methods for evaluating the Weibull parameters as MWS, MLM, MMLM, GM and PD methods.

\section{Error Analysis of Wind Speed Modelling Based on Averaged Monthly Data}

The error of the previous methods for evaluating the Weibull distribution parameters have been addressed in the following table, Table (4), by calculating the RMSE 


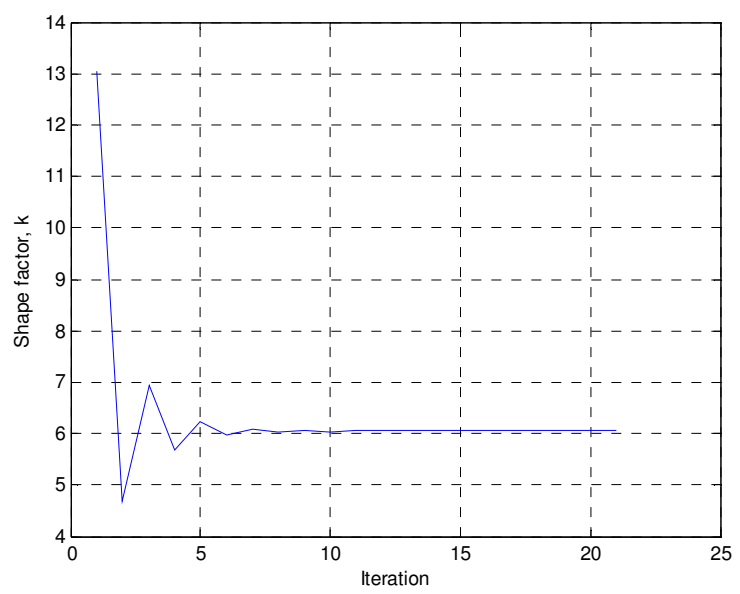

Fig. 11. Estimating the Weibull distribution shape-factor variation of the shape factor with the iterations, MLM.

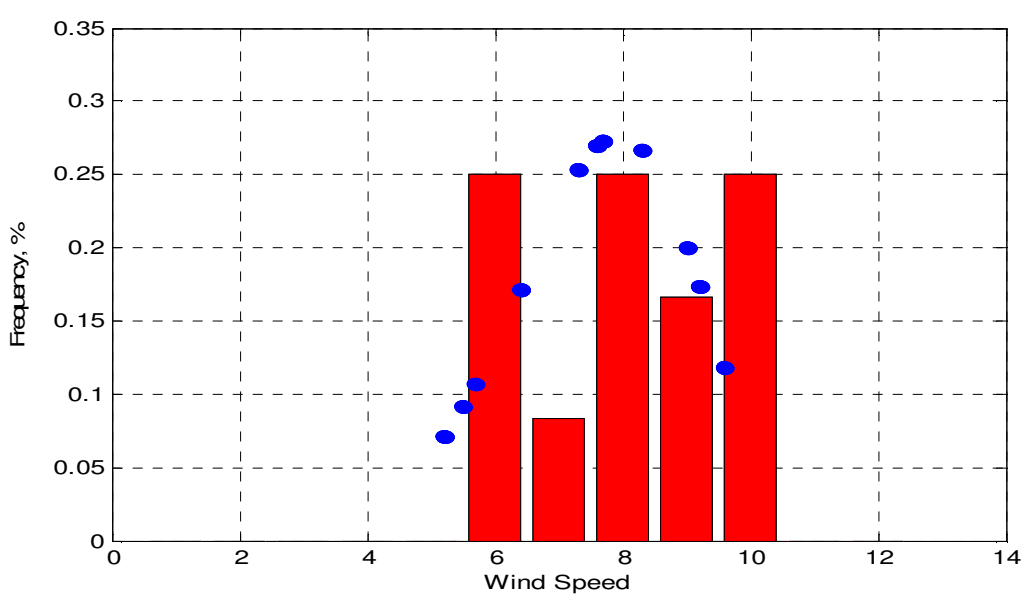

Fig. 12. Estimating the Weibull distribution shape-factor using MLM, comparison between the collected data probability, bars, and the estimated Weibull distribution function, circles.

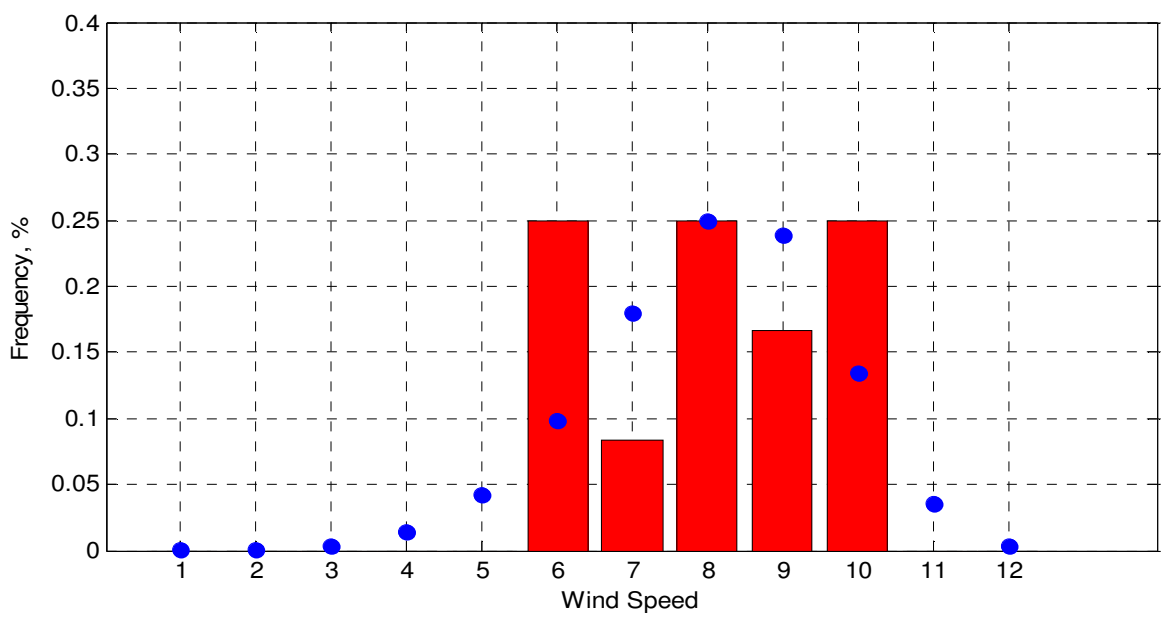

Fig.13. Estimating the Weibull distribution shape-factor using MMLM, comparison between the collected data probability, bars, and the estimated Weibull distribution function, circles. 


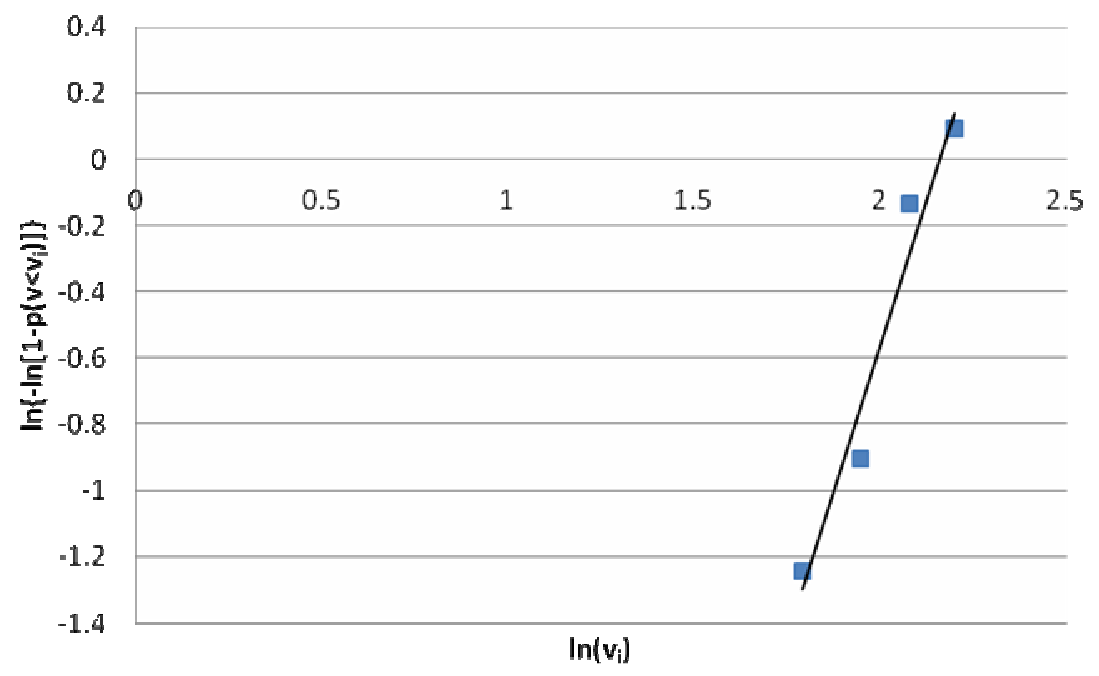

Fig. 14. Estimating the Weibull distribution parameters using the Graphical method.

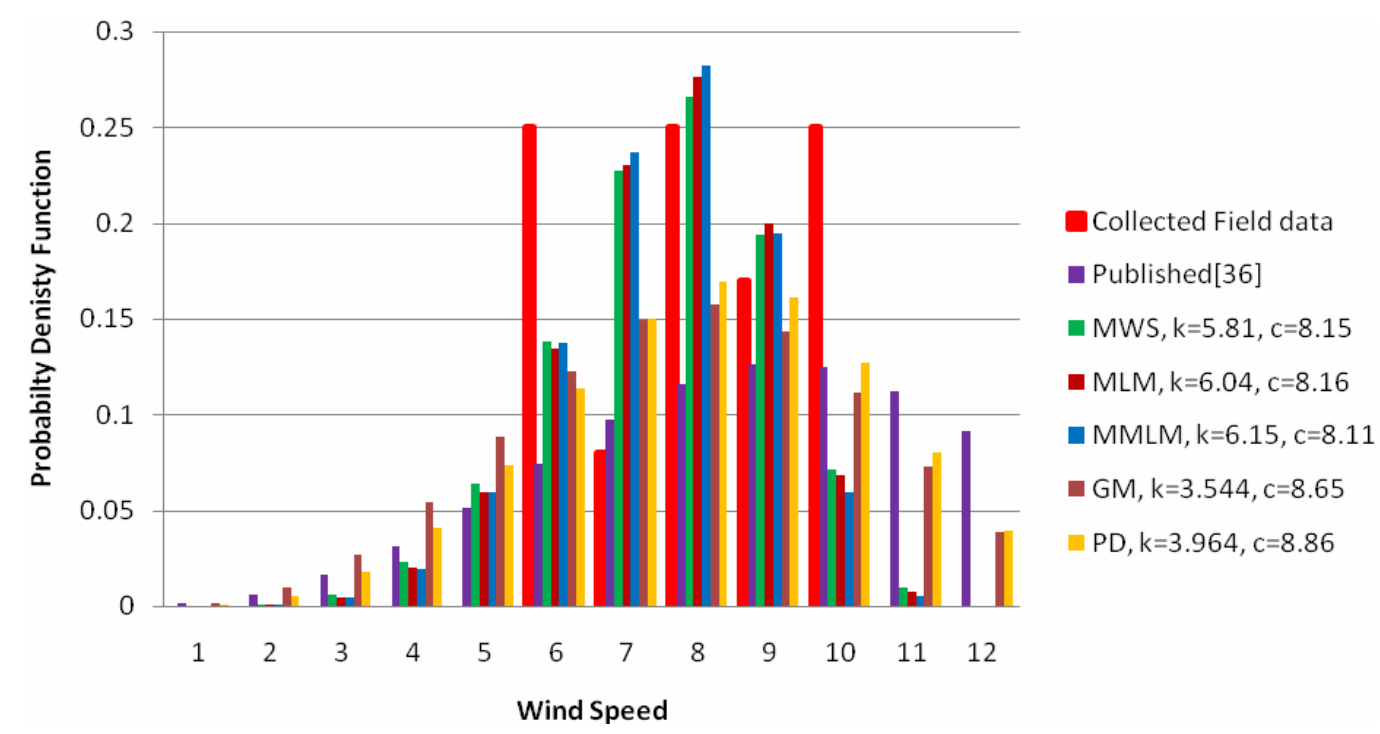

Fig. 15. Comparison between the Weibull distributions based on different methods for estimating the distribution parameters, averaged monthly wind speed.

Table.3. Weibull distribution parameters values for different methods, based on averaged monthly wind speed for one year from July 2010 to June 2011.

\begin{tabular}{|c|c|c|}
\hline \multirow{2}{*}{ Method } & \multicolumn{2}{|c|}{ Weibull distribution Parameter } \\
\cline { 2 - 3 } & $\begin{array}{c}\text { Shape factor } \\
\text { K, [-] }\end{array}$ & $\begin{array}{c}\text { Scale factor } \\
\mathbf{C},[\mathrm{m} / \mathbf{s}]\end{array}$ \\
\hline Moussa (2000) & 3.42 & 10.4 \\
\hline MWS & 5.806 & 8.15 \\
\hline MLM & 6.04 & 8.16 \\
\hline MMLM & 6.15 & 8.11 \\
\hline GM & 3.544 & 8.65 \\
\hline PD & 3.964 & 8.89 \\
\hline
\end{tabular}


between the estimated probability value and the wind farm field data as follows :

$R M S E=\sqrt{\left(V_{a c}-V_{M}\right)^{2}}$

where $V_{a c}$ is the actual wind speed data and $V_{M}$ is the modelled wind speed using Weibull distribution.

Table.4. RMSE for different methods for estimating the Weibull distribution parameters

\begin{tabular}{|c|c|c|c|c|c|c|}
\hline Method & $\begin{array}{c}\text { Moussa } \\
\text { (2000) }\end{array}$ & MWS & MLM & MMLM & GM & PD \\
\hline $\begin{array}{c}\text { Averaged } \\
\text { RMSE }\end{array}$ & 0.06708 & 0.0476 & 0.0498 & 0.0506 & 0.06225 & 0.0558 \\
\hline
\end{tabular}

The minimum averaged error for the selected method, either MWS or MLM, is about $4.7 \%$ from the actual measured averaged monthly wind speed.

\section{Statistical Modelling of Wind Speed Based on Averaged Hourly Data}

The measured wind speed every 10 minutes from Zafarana Wind Farm measured in two selected days; one day in summer, $10^{\text {th }}$ of July 2010 and the other day in winter, $10^{\text {th }}$ of March 2011, has been analyzed using different method to estimate the Weibull parameters using a Matlab program by iterations then comparison between these different methods have been made as shown in Figs. 16 to 19.

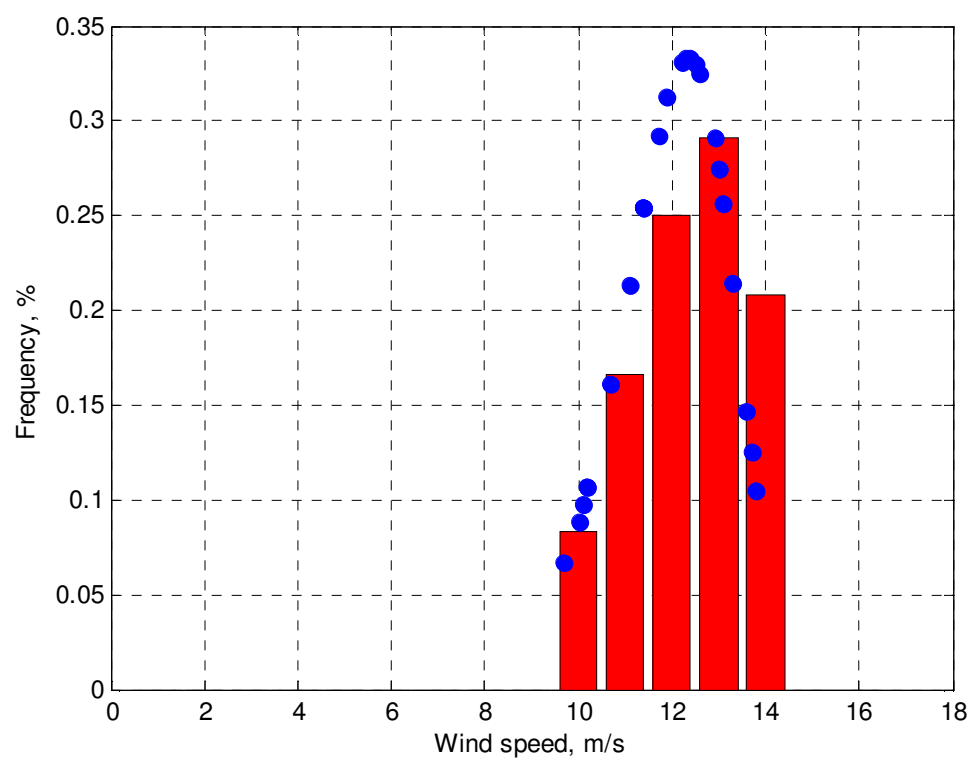

Fig.16. Estimating the Weibull distribution shape-factor using MLM, comparison between the collected data probability, bars, and the estimated Weibull distribution function, circles, data for hourly averaged wind speed in summer season. 


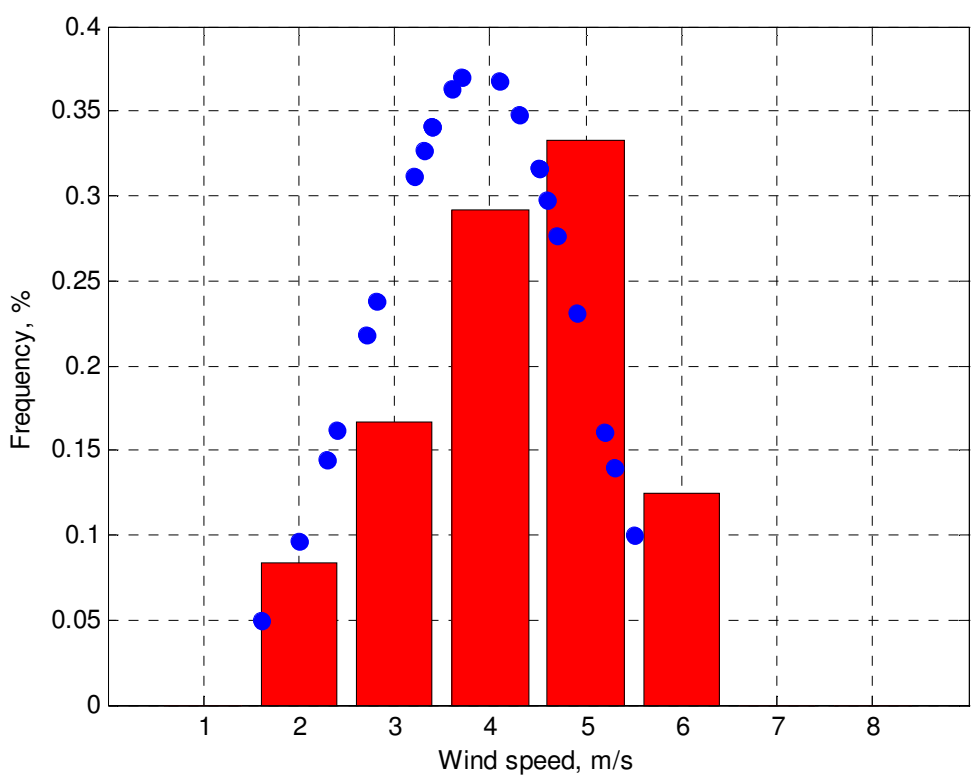

Fig.17. Estimating the Weibull distribution shape-factor using MLM, comparison between the collected data probability, bars, and the estimated Weibull distribution function, circles, data for hourly averaged wind speed in winter season.

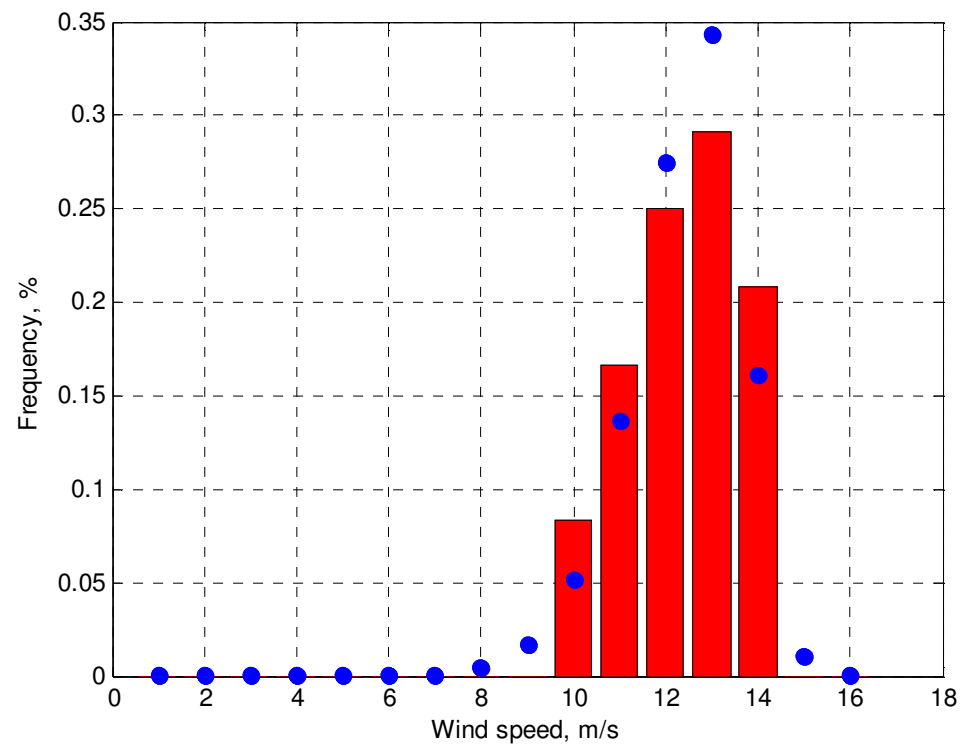

Fig.18. Estimating the Weibull distribution shape-factor using MMLM, comparison between the collected data probability, bars, and the estimated Weibull distribution function, circles, data for hourly averaged wind speed in summer season. 


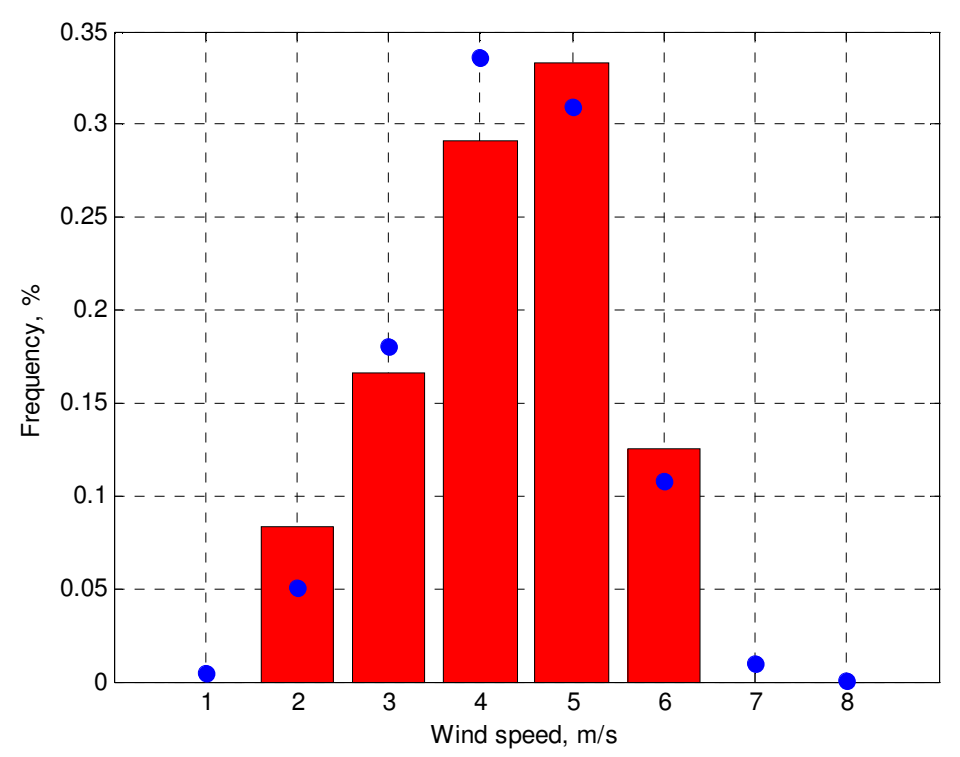

Fig.19. Estimating the Weibull distribution shape-factor using MMLM, comparison between the collected data probability, bars, and the estimated Weibull distribution function, circles, data for hourly averaged wind speed in winter season.

In Figs. 20 and 21, comparisons have been made for the collected data for the wind speed and that modeled based on hourly data using Weibull distribution introducing different methods for evaluating the Weibull parameters as MWS, MLM, MMLM, GM and PD methods.

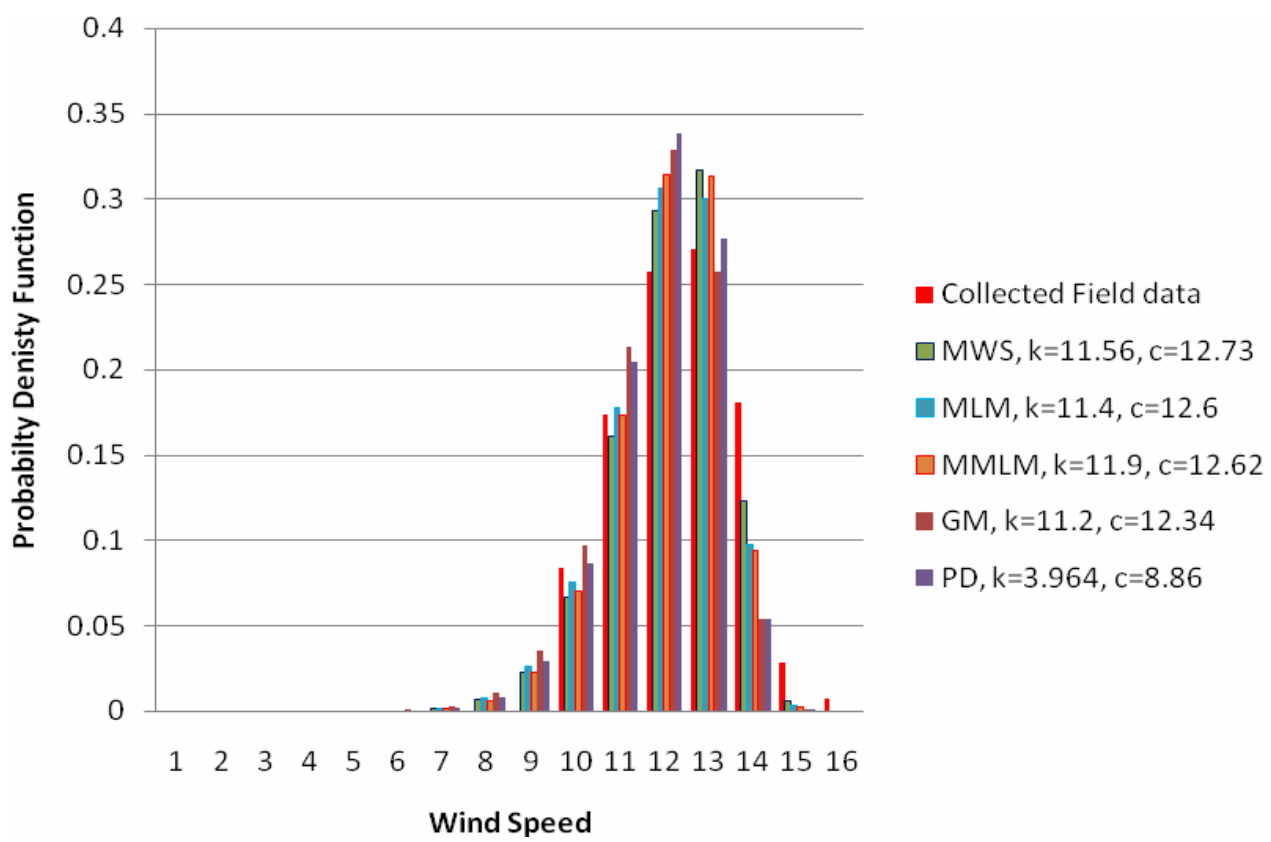

Fig. 20. Comparison between the Weibull distributions based on different methods for estimating the distribution parameters, averaged monthly wind speed, data for hourly averaged wind speed in summer season. 


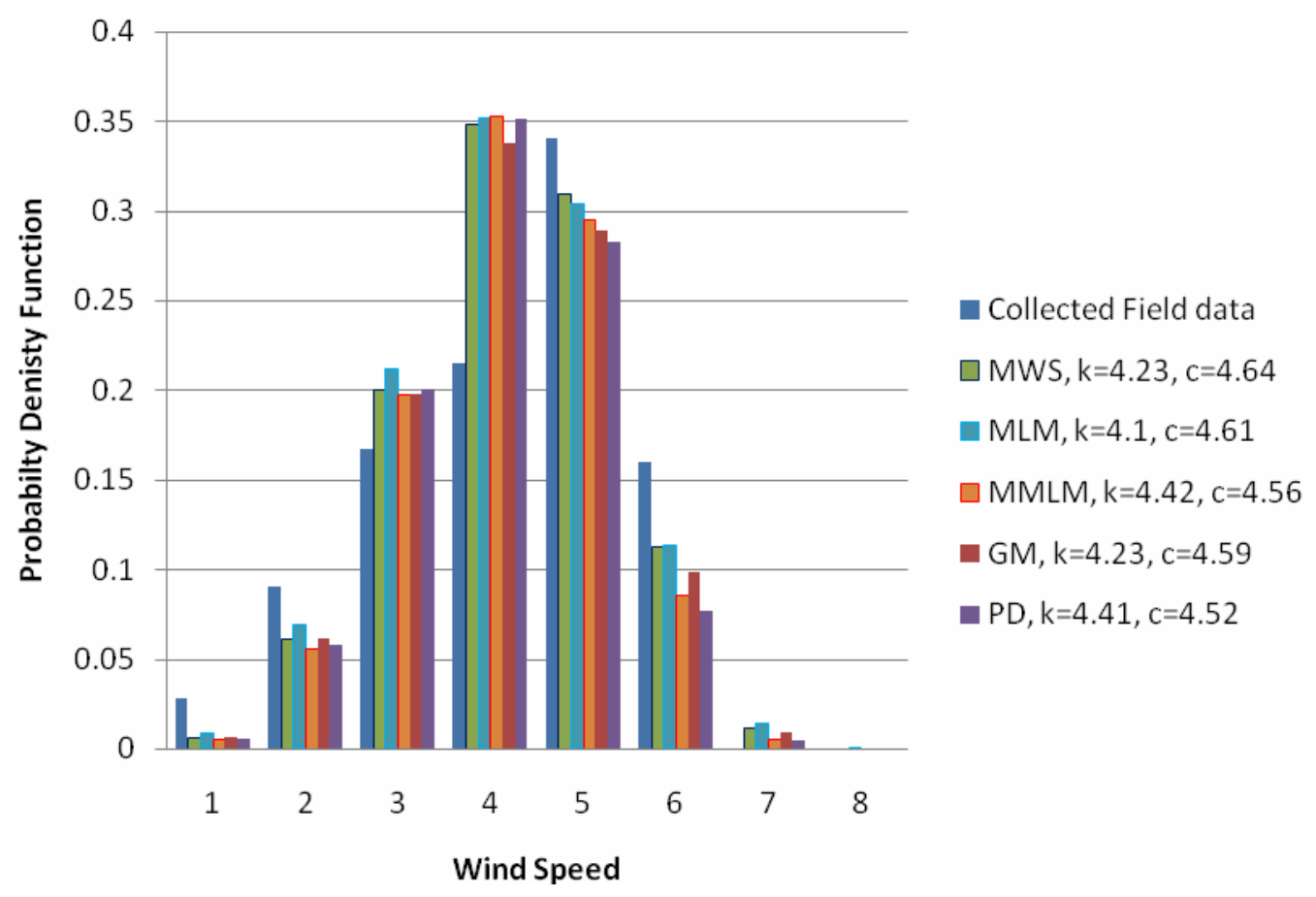

Fig.21. Comparison between the Weibull distributions based on different methods for estimating the distribution parameters, averaged monthly wind speed, data for hourly averaged wind speed in winter season.

Table.5. Weibull distribution parameters values for different methods, averaged monthly wind speed, data for hourly averaged wind speed in summer season and winter season.

\begin{tabular}{|c|c|c|c|c||}
\hline \multirow{2}{*}{ Method } & \multicolumn{2}{|c|}{ Summer Season } & \multicolumn{2}{c|}{ Winter Season } \\
\cline { 2 - 5 } & $\begin{array}{c}\text { Shape factor } \\
\text { K, [-] }\end{array}$ & $\begin{array}{c}\text { Scale factor } \\
\mathbf{C},[\mathbf{m} / \mathbf{s}]\end{array}$ & $\begin{array}{c}\text { Shape factor } \\
\text { K, [-] }\end{array}$ & $\begin{array}{c}\text { Scale factor } \\
\mathbf{C},[\mathbf{m} / \mathbf{s}]\end{array}$ \\
\hline MWS & 11.56 & 12.73 & 4.23 & 4.64 \\
\hline MLM & 11.4 & 12.6 & 4.1 & 4.61 \\
\hline MMLM & 11.9 & 12.62 & 4.42 & 4.56 \\
\hline GM & 11.2 & 12.34 & 4.23 & 4.59 \\
\hline PD & 11.8 & 12.4 & 4.41 & 4.52 \\
\hline
\end{tabular}

\section{Error Analysis of Wind Speed Modelling Based on Averaged Hourly Data}

Table.6. RMSE for different methods for estimating the Weibull distribution parameters, data for hourly averaged wind speed in summer season.

\begin{tabular}{|c|c|c|c|c|c|}
\hline Method & MWS & MLM & MMLM & GM & PD \\
\hline \hline $\begin{array}{c}\text { Averaged } \\
\text { RMSE }\end{array}$ & 0.0143 & 0.0151 & 0.0165 & 0.0217 & 0.0187 \\
\hline
\end{tabular}


Table.7. RMSE for different methods for estimating the Weibull distribution parameters, data for hourly averaged wind speed in winter season.

\begin{tabular}{|c|c||c|c|c|c|}
\hline Method & MWS & MLM & MMLM & GM & PD \\
\hline \hline $\begin{array}{c}\text { Averaged } \\
\text { RMSE }\end{array}$ & 0.0382 & 0.0397 & 0.0437 & 0.0407 & 0.0461 \\
\hline
\end{tabular}

It could be concluded that the MWS and MLM methods are recommended in evaluating the Weibull distribution parameters for Zafarana wind farm, Site-3, based on the RMSE for these methods. The minimum averaged error for the selected method, either MWS or MLM, was about $1.6 \%$ from the actual measured averaged monthly wind speed in the summer season while it was $3.9 \%$ from the actual measured averaged monthly wind speed in the winter season. This conclusion is in good agreement as the results published in (Ali, 2003) and (Islam et al., 2010) but for different wind sites.

\section{CONCLUSION}

The distribution of the measured wind speed of averaged monthly data for one year from July 2010 to June 2011 as well as every 10 minutes for two days, one day in summer season $10^{\text {th }}$ of July 2010 and one day in winter season $10^{\text {th }}$ of March 2011 , are well approximated by Weibull density function.

Assessment of different methods as mean wind speed, maximum likelihood method, modified maximum likelihood method, graphical method, power density method, are used to estimate the Weibull distribution parameters for monthly averaged and daily averaged.

Based on the RMSE, the mean wind speed and maximum likelihood method are recommended methods to estimate the Weibull distribution parameters to find the wind speed distribution for wind speed analysis purposes. These parameters were estimated for Zafarana wind farm in Site-3.

In addition, the results of the study are compared to published data as a tool to evaluate the performance of a wind farm in this site; this conclusion is in good agreement with the previously published results but for different sites.

\section{ACKNOWLEDGEMENT}

The authors would like to thank the New and Renewable Energy Authority (NREA) in Egypt for their support and providing the necessary field measurement to complete this work which enrich and enhance the article.

\section{REFERENCES}

[1] Akdag, S.A., Dinler, A., 2009 "A new method to estimate Weibull parameters for wind energy applications”, Energy Conversion and Management 50. 
[2] Akpinar, E.K., Akpinar, A., 2004 "An assessment on seasonal analysis of wind energy characteristics and wind turbine characteristics", Energy Conversion and Management 46.

[3] Celik, A.N., 2003 "Weibull representative compressed wind speed data for energy and performance calculations of wind energy systems", Energy Conversion and Management 44.

[4] Celik Ali Naci, 2004 "Energy output estimation for small-scale wind power generators using Weibull-representative wind data", Journal of Wind Engineering and Industrial Aerodynamics 91.

[5] Tsang-Jung Chang , Yu-Ting Wu , Hua-Yi Hsu ,Chia-Ren Chu , Chun-Min Liao , 2003 "Assessment of wind characteristics and wind turbine characteristics in Taiwan", Renewable Energy 28.

[6] Chang, T.P., 2011 "Performance comparison of six numerical methods in estimating Weibull parameters for wind energy application", Applied Energy 88.

[7] Dorvlo, A.S., 2002 "Estimating wind speed distribution", Energy Conversion and Management 43.

[8] Ettoumi Y., F., H. Sauvageot , A.-E.-H. Adane, 2003 "Statistical bivariate modelling of wind using first-order Markov chain and Weibull distribution", Renewable Energy 28.

[9] Islam, M.R., Saidur, R. and Rahim, N.A., 2011 "Assessment of wind energy potentiality at Kudat and Labuan, Malaysia using Weibull distribution function", Energy 36, 985-992.

[10] Jowder Fawzi A.L., 2009 "Wind power analysis and site matching of wind turbine generators in Kingdom of Bahrain", Applied Energy 86.

[11] Kiss Péter, Jánosi Imre M., 2008 "Comprehensive empirical analysis of ERA40 surface wind speed distribution over Europe", Energy Conversion and Management 49.

[12] Moussa, A. 2000 'Wind Energy in Egypt', DEWI Magazin No. 17.

[13] Mirhosseini M., F. Sharifi, A. Sedaghat , 2011 "Assessing the wind energy potential locations in province of Semnan in Iran", Renewable and Sustainable Energy Reviews 15.

[14] Perez I.A., M.A. Garcia, M.L. S , anchez, B. de Torre , 2004 "Analysis of height variations of sodar-derived wind speeds in Northern Spain", Journal of Wind Engineering and Industrial Aerodynamics 92 .

[15] Toure Siaka, 2005 "Investigations on the Eigen-coordinates method for the 2parameter weibull distribution of wind speed", Renewable Energy 30.

[16] Vogiatzis N., K. Kotti , S. Spanomitsios, M. Stoukides, 2004 "Analysis of wind potential and characteristics in NorthAegean", Greece, Renewable Energy 29.

[17] Xiao Y. Q.,Q.S.Li ,Z.N.Li ,Y.W.Chow ,G.Q.Li , 2006 "Probability distributions of extreme wind speed and its occurrence interval", Engineering Structures 28. 